\title{
HUBUNGAN BIMBINGAN KARIR DAN KEPERCAYAAN DIRI DENGAN PERENCANAAN KARIR PESERTA DIDIK KELAS XII MIPA SMA NEGERI 2 TEGAL
}

\author{
Essa Putra Lukita, Hastin Budisiwi, Hanung Sudibyo \\ FKIP-UniversitasPancasaktiTegal
}

\begin{abstract}
Abstrak
Tujuan dari penelitian ini adalah untuk mengetahui hubungan antara bimbingan karir dan kepercayaan diri dengan perencanaan karir pada peserta didik kelas XII MIPA SMA Negeri 2 Tegal Tahun Pelajaran 2020/2021. Penelitian ini menggunakan pendekatan kuanitatif. Teknik sampling yang digunakan dalam penelitian ini adalah teknik probably sampling dengan jenis simple random sampling. Adapun cara pengambilan data yaitu dengan menggunakan teknik observasi,kuesioner dan dokumentasi. Berdasarkan data yang diperoleh terdapat hubungan antara bimbingan karir dengan perencanaan karir. Hal ini ditunjukan dari nilai Koefisien regresi variabel bimbingan karir yaitu bernilai positif sebesar 0,82; artinya jika bimbingan karir mengalami kenaikan 1\%, maka perencanaan karir akan mengalami peningkatan sebesar 0,82 . Semakin tinggi bimbingan karir maka semakin tinggi perencanaan karir peserta didik. Sama halnya dengan kepercayaan diri, terdapat hubungan kepercayaan diri dengan perencanaan karir. Hal ini ditunjukan dari nilai Koefisien regresi variabel kepercayaan diri yaitu bernilai positif sebesar 0,041; artinya jika kepercayaan diri mengalami kenaikan 1\%, maka perencanaan karir akan mengalami peningkatan sebesar 0,041. Semakin tinggi bimbingan karir maka semakin tinggi perencanaan karirpeserta didik.

Berdasarkan hasil penelitian, terdapat hubungan positif antara variabel bimbingan karir, kepercayaan diri dan perencanaan karir. Hal ini ditunjukan dari perhitungan uji regresi bersama-sama (Uji F), nilai Fhitung adalah 5,04. Jadi nilai Fhitung $>$ Ftabel atau 5,04 > 3,47, artinya H03 ditolak dan Ha3 diterima. Berdasarkan uji F yang telah dilakukan, maka dapat disimpulkan bahwa terdapat hubungan yang positif dan signifikan antara bimbingan karir dan kepercayaan diri dengan perencanaan karir pada peserta didik kelas XII MIPA SMA Negeri 2 Tegal Tahun Pelajaran 2020/2021.
\end{abstract}

Kata kunci : metode montessori, perkembangan anak, bimbingan dan konseling anak

\begin{abstract}
The purpose of this study was for determine the relationship between career guidance and confidence with career planning at class XII Mathematics learners SMA 2 Tegal in the academic year 2020/2021. This study uses a quantitative approach. Technique sampling that used in reseach this is a technique probably sampling the types of simple random sampling. The method for taking data is using of observation, questionnaires and documentation

Based on the data obtained, there is a relationship between career guidance and career planning. This is indicated by the regression coefficient of the career guidance variable, which is positive at 0.82; it means that if career guidance has increased by $1 \%$, then career planning will increase by 0.82 . The higher the career guidance, the higher the career planning of students. As with self-confidence, there is a relationship between self-confidence and career planning. This is indicated by the value of the regression coefficient of the self-confidence variable, which is positive at 0.041; This means that if self-confidence increases by 1\%, then career planning will increase by 0.041. The higher the career guidance, the higher the career planning of students.

Based on the results of the study, there is a positive relationship between the variablesof career guidance, self confidence and career planning. It is shown from the calculation of the test regression together ( $F$ test), the value of $F$ is 5,04, so the value of $F$ count $>F$ table or 5,04 ? 4,47, meaning H03rejected and Ha3is received. Based on the test $F$ that has been done, it can be concluded that there is a relationship that is positive and significant between guidance career and self confidence wiht planning career in the participant students grade XII SMAN 2 Tegal.Key: Montessori method, child development, child guidance and counseling Keywords: Career Guidance, Confidence, Career Planning
\end{abstract}




\section{PENDAHULUAN}

Pada hakekatnya kebahagiaan menjadi hal yang penting dan sangat berarti dari segala usaha dan upaya yang dilakukan oleh manusia.Kebahagiaan dalam hal ini salah satunya adalah mendapatkan pendidikan yang layak untuk mengantarkannya menuju karir yang gemilang dimasa depan. Berdasarkan Undang-undang Pendidikan Nasional No. 20 Tahun 2003 dijelaskan bahwa pendidikan nasional berfungsi mengembangkan kemampuan dan membentuk watak serta peradaban bangsa yang bermartabat dalam rangka mencerdaskan kehidupan bangsa, serta berfungsi untuk berkembangnya potensi peserta didik agar menjadi manusia yang beriman dan bertakwa kepada Tuhan Yang Maha Esa, berakhlak mulia, sehat, berilmu, cakap, kreatif, mandiri, dan menjadi warga Negara yang demokratis serta bertanggung jawab.

Sekolah tidak hanya berfungsi memberikan pengetahuan secara teori dalam kegiatan belajar mengajar di kelas, tetapi juga dapat memberikan bimbingan dan pengembangan seluruh kemampuan peserta didik seperti membantu perencanaan karir lanjutan peserta didik setelah lulus sekolah. Layanan ini digunakan agar peserta didik memiliki pengetahuan yang memadai, baik tentang dirinya maupun lingkungannya, dan sumber-sumber ilmu pengetahuan yang lain, sehingga lebih memudahkan peserta didik dalam membuat perencanaan karir dan mengambil keputusan. Pemilihan karir merupakan hal yang harus diputuskan dengan pertimbangan yang tepat dan juga dilakukan guna kelanjutan aktifitas kehidupan dengan keyakinan bahwa pilihan yang diambil adalah pilihan yang terbaik. Menurut Hastin (2018) kematangan karir memiliki pengertian sebagai proses yang menimbulkantingkah lakuyang barusebagai akibat dari pertumbuhan dan perkembangan.Pemberian layanan bimbingan karir pada peserta didik kelas XII MIPA SMA Negeri 2 Tegal mengalami kendala karena tidak dapat dilakukan secara tatap muka dengan peserta didik dikarenakan adanya pandemi covid-19, meskipun layanan bimbingan karir dilakukan secara daring, guru bimbingan dan konseling membantu peserta didik dalam hal perencanaan karir lanjutan melalui analisis data nilai raport peserta didik yang kemudian akan membantu peserta didik untuk mempertimbangkan dan mengambil keputusan karir lanjutan sesuai dengan minat, bakat, dan kemampuan peserta didik.

Temuan dilapangan menunjukan bahwa peserta didik masih bingung akan melanjutkan pendidikan atau bekerja. Selain itu, juga terdapat pula beberapa orang tua peserta didik yang melakukan konsultasi terkait karir lanjutan anaknya kepada guru bimbingan dan konseling melalui handphone, kemudian guru bimbingan dan konseling merespon dengan hal yang serupa yaitu meminta orang tua peserta didik untuk mengirimkan foto hasil nilai raport dari kelas X hingga kelas XII, untuk dianalisis dan kemudian disarankan kepada orang tua dan peserta didik. Pilihan karir yang dapat dipilih oleh peserta didik kelas XII yaitu melanjutkan ke perguruan tinggi atau terjun ke dunia kerja.

Berdasarkan latar belakang masalah yang dikemukakan diatas, makapeneliti tertarik untuk melakukan penelitian lebih dalam mengenai "Hubungan Bimbingan Karir dan Kepercayaan Diri dengan Perencanaan Karir Peserta Didik Kelas XII MIPA SMA Negeri 2 Tegal Tahun Pelajaran 2020/2021”.

\section{METODE}

Bimbingan karir merupakan salah satu jenis bimbingan yang berusaha membantu individu dalam memecahkan masalah karir, untuk memperoleh penyesuaian diri yang sebaik-baiknya antara kemampuan dengan lingkungan hidupnya, memperoleh keberhasilan dan perwujudan diri dalam perjalanan hidupnya (Surya 2016: 210).Secara umum tujuan bimbingan karir disekolah ialah membantu siswa dalam pemahaman dirinya dan lingkungannya dalam pengmbilan keputusan, perencanaan dan pengarahan kegiatan-kegiatan yang menuju kepada karir dan cara hidup. Percaya diri berasal dari bahasa inggris "self confidence" yang artinya percaya pada kemampuan atau kekuatan dan penilaian diri sendiri, jadi dapat dikatakan bahawa penilaian tentang diri sendiri adalah berupa penilaian yang positif. Idrus dan Rohmati (2010:1) menyatakan bahwa kepercayaan diri merupakan aspek kepribadian manusia yang penting sebagai sarana untuk mengaktualisasikan potensi yang dimiliki. Dari kepercayaan diri yang dimiliki, kesuksesan dan keberhasilan hidup seseorang akan dapat diprekdisikan.Individu yang percaya diri biasannya selalu bersikap optimis dan yakin akan kemampuannya dalam melakukan sesuatu. Sebaiknya individu yang rasa percaya dirinya rendah akan mengalami hambatan- hambatan dalam hidupnya ,baik dalam berinteraksi dengan individu lain maupun dalam pekerjaan. 
Perencanaan karir adalah suatu perencanaan tentang kemungkinan-kemungkinan seseorang atau anggota organisasi sebagai individu meniti proses kenaikan pangkat atau jabatan sesuai dengan persyaratan dan kemampuannya. Suatu perencanaan karir harus dilandasi penyusunan persyaratanpersyaratan yang harus dimiliki oleh seseorang, guna mendukung peningkatan karirnya. Menurut Parson dalam Atmaja (2014) perencanaan karir adalah suatu cara untuk membantu siswa dalam memilih suatu bidang karir yang sesuai dengan potensi, sehingga dapat cukup berhasil di bidang pekerjaan. Perencanaan karir perlu disiapkan sebelum siswa terjun secara langsung dalam dunia karir.dalam merencanakan karir terdapat faktor yang memperngaruhi baik internal maupun eksternal yang masing-masing saling berhubungan dan tidak dapat dipisahkan. Faktor internal dalam perencanaan karir meliputi nilai-nilai kehidupan, taraf inteligensi, bakat khusus, minat, pengetahuan dan keadaan jasmani. Sedangkan faktor eksternal dalam perencanaan karir meliputi masyarakat, keadaan sosial-ekonomi suatu negara atau daerah, status sosial-ekonomi keluarga, pengaruh dari semua keluarga besar dan keluarga inti, pendidikan sekolah, pergaulan dengan teman sebaya serta tuntutan yang melekat pada masing-masing jabatan dan pada setiap program studi atau latihan

Pendekatan yang digunakan dalam penelitian ini adalah kuantitatif dengan Jenis penelitian korelasi. Penelitian korelasional adalah penelitian yang dimaksudkan untuk mengetahui ada tidaknya hubungan antara dua atau beberapa variabel pada suatu studi kelompok subjek.

Waktu dan Tempat Penelitian. Penelitian dilaksanakan pada tanggal 31 Maret 2021-10 Juni 2021 bertempat di SMAN 2 Kota Tegal yang berlokasi di Jalan Lumba-Lumba No. 24, Tegalsari, Kec. Tegal Barat, Kota Tegal Prov. Jawa Tengah. Populasi adalah wilayah generalisasi yang terdiri atas obyek atau subyek yang mempunyai kualitas dan karakteristik tertentu yang ditetapkan oleh peneliti untuk dipelajari kemudian ditarik kesimpulannya (Sugiyono, 2015:117). Dalam penelitian ini yang menjadi populasi adalah kelas XII MIPA SMAN 2 Tegal Tahun Pelajaran 2020/2021 yang terdiri dari kelas XII MIPA 1, XII MIPA 2, XII MIPA 3, XII MIPA 4, dan XII MIPA 5 dengan jumlah keseluruhan sebanyak 145 peserta didik.Teknik sampling yang digunakan dalam penelitian ini adalah teknik probably sampling dengan jenis simple random sampling. Probably sampling adalah teknik pengambilan sampel yang memberikan peluang yang sama bagi setiap unsur (anggota) populasi untuk dipilih menjadi anggota sampel. Dikatakan Simple random sampling karena pengambilan anggota sampel dari anggota populasi dilakukan secara acak tanpa memperhatikan strata yang ada dalam populasi tersebut (Sugiyono, 2015:120). Dalam penelitian ini yang menjadi sampel adalah kelas XII MIPA 1 dengan jumlah 30 Peserta didik, hal ini dikarenakan kelas XII merupakan peserta didik yang akan segera lulus sehingga perlu memiliki gambaran atau perencanaan karir. Selain itu, berdasarkan pengamatan guru mata pelajaran dan guru BK kelas XII MIPA 1 didominasi oleh peserta didik yang pendiam dan tidak mudah mengemukakan pendapatnya Teknik pengumpulan data dalam penelitian ini dengan menggunakan skala (kuesioner) sebagai metode pokok untuk memperoleh data utama, observasi dan dokumentasi sebagai teknik pendukung. Teknik analisis data dalam penelitian ini yaitu uji prasayarat analisis untuk menentukan jenis statistik yang digunakan apakah menggunakan statistik parametrik atau non parametrik. Uji prasyarat yang digunakan meliputi uji normalitas, uji linieritas dan uji homogenitas selanjutnya untuk menjawab hipotesis penelitian digunakan analisis regresi sederhana dan analisis regresi berganda.

\section{HASIL DAN PEMBAHASAN}

Bimbingan karir adalah suatu proses dimana pelajar diberi arahan dan bimbingan untuk kehidupannya dimasa yang akan datang. Bimbingan karir merupakan metode pembelajaran yang mengacu pada pemahaman jenjang karir dimasa depan. Melalui bimbingan karir peserta didik dapat mendapatkan informasi mengenai pengenalan diri, pemahaman dunia kerja, pemilihan dan keputusan tentang karir yang lebih tepat (Gani dalam Hasanah, 2018). Fenomena yang terjadi pada peserta didik SMA salah satunya adalah masalah karir, karena peserta didik SMA merasa belum memiliki kepastian dalam mengambil langkah setelah kelulusan. Hayadin (dalam Islamadina dan Yulianti, 2016) menunjukkan sebesar $64,25 \%$ peserta didik SMA, MA, dan SMK belum memiliki keputusan yang jelas mengenai profesi yang akan diambilnya. 
Kepercayaan diri adalah suatu sikap atau perasaan yakin atas kemampuan diri sendiri. Pengambilan keputusan karir merupakan suatu proses untuk menentukan pilihan dari berbagai alternatif yang berkaitan dengan pekerjaan. Semakin tinggi tingkat kepercayaan diri peserta didik maka semakin baik pengambilan keputusan karir peserta didik, dan sebaliknya semakin rendah tingkat kepercayaan diri peserta didik maka semakin rendah maka kurang tepat pengambilan keputusan karir peserta didik (Hadi ,2019). Kepercayaan diri pada dasarnya adalah kemampuan dasar untuk dapat menentukan arah dan tujuan dalam sebuah kehidupan. Kepercayaan diri merupakan salah satu aspek kepribadian yang berupa keyakinan akan kemampuan diri, seseorang memiliki pandangan dan harapan yang positif mengenai diri dan masa depannya, mampu menghadapi segala persoalan dengan kemampuan pola pikir yang positif serta mampu menerima kenyataan dari sebuah kegagalan yang dialaminya. Dari penjelasan di atas dapat disimpulkan bahwa seseorang yang memiliki rasa percaya diri mampu menerima kenyataan, dapat mengembangkan kesadaran diri, berfikir secara positif, memiliki kemandirian dan kemampuan untuk memiliki serta mencapai segala sesuatu yang diinginkan. Dalam menentukan pengambilan keputusan karir maka seseorang harus merasa yakin akan kemampuan yang dimiliki, ketika seseorang tidak yakin akan kemampuan yang dimiliki maka akan sulit dalam merencanakan atau mengambil sebuah keputusan terutama dalam merencanakan karir dimasa depan.

Berdasarkan hasil penelitian, terdapat hubungan positif antara variabel bimbingan karir, kepercayaan diri dan perencanaan karir. Hal ini ditunjukan dari perhitungan uji regresi bersama-sama (Uji F), nilai Fhitung adalah 5,04. Jadi nilai Fhitung $>$ Ftabel atau 5,04 > 3,47, artinya H03 ditolak dan Ha3 diterima. Jadi, hipotesis terdapat hubungan yang positif dan signifikan antara bimbingan karir dan kepercayaan diri dengan perencanaan karir pada peserta didik kelas XII MIPA SMA Negeri 2 Tegal Tahun Pelajaran 2020/2021 terbukti atau diterima. Berdasarkan uji F yang telah dilakukan, maka dapat disimpulkan bahwa terdapat hubungan yang positif dan signifikan antara bimbingan karir dan kepercayaan diri dengan perencanaan karir pada peserta didik kelas XII MIPA SMA Negeri 2 Tegal Tahun Pelajaran 2020/2021.

\section{SIMPULAN}

Terdapat hubungan antara bimbingan karir dengan perencanaan karir pada peserta didik kelas XII MIPA SMA Negeri 2 Tegal Tahun Pelajaran 2020/2021. Semakin tinggi pelaksanaan bimbingan karir maka semakin tinggi perencanaan karir peserta didik. Terdapat hubungan kepercayaan diri dengan perencanaan karir pada peserta didik kelas XII MIPA SMA Negeri 2 Tegal Tahun Pelajaran 2020/2021. Semakin tinggi kepercayaan diri maka semakin tinggi perencanaan karir peserta didik.. Terdapat hubungan antara bimbingan karir dan kepercayaan diri dengan perencanaan karir pada peserta didik kelas XII MIPA SMA Negeri 2 Tegal Tahun Pelajaran 2020/2021.

\section{DAFTAR PUSTAKA}

Atmaja, T. T. (2014). Upaya Meningkatkan Perencanaan Karir Siwa Melalui Bimbingan Karir Dengan

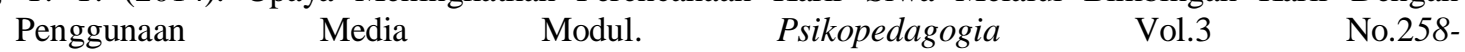
67.https://core.ac.uk/download/pdf/324200484.pdf

Budisiwi, H. (2018, November). Kematangan Karir Menggunakan Tes Mi Sebagai Pendukung Tes Sds Pada Mahasiswa Universitas Pancasakti Tegal. In Seminar Nasional Bimbingan Konseling (Vol. 2, No. 1, pp. 22-27). https://fip.unesa.ac.id/fipppti/public/proceeding/index.php/prosidingsemnasbk/article/view/64

Hadi, E. O. A., Latifah, L., \& Santoso, D. B. (2019, December). Hubungan Antara Kepercayaan Diri Dengan Pengambilan Keputusan Karir Siswa. In Prosiding Seminar Nasional Fakultas Ilmu Pendidikan (Vol. 3, pp. 424-427).https://conference.unikama.ac.id/artikel/index.php/fip/article/view/273

Hasanah, H., Rahmawati, W. K., \& Damayanti, N. E. (2019). Pengaruh Layanan Bimbingan Karir Terhadap Perencanaan Karir Siswa Kelas XI IPS 2 SMA Negeri Pasirian Kabupaten Lumajang Tahun Ajaran 2017/2018. Success: Jurnal bimbingan konseling dan pendidikan, 1(2), 7090.https://jurnal.ikipjember.ac.id/index.php/success/article/view/263 
Rokhayati, A., Kambara, R., \& Ibrahim, M. (2017). Pengaruh Soft Skill Dan Perencanaan Karirterhadap Kinerja Karyawan Dengan Kualitas Pelatihan Sebagai Variabel Modertor. Jurnal Riset Bisnis Dan Manajemen Tirtayasa (JRBMT),Vol.1,107-124.https://jurnal.untirta.ac.id/index.php/JRBM/article/view/3147

Sugiyono.2015.Metode Penelitian Kuantitatif, Kualitatif, dan E\&D. Bandung:Alfabetha 